\title{
Convivência da família com o indivíduo com esquizofrenia
}

\author{
Raquel Juliana de Oliveira Soares, M.Sc.*, Fátima Cristina Alves Araújo, M.Sc.*, Flávia Mourão da Silva**, \\ Giselle de Sá Cavalcanti Werneck**, Mariana de Assis Galdino**
}

*Enfermeira, Docente da Universidade Estácio de SálRJ, **Acadêmica de Enfermagem, Universidade Estácio de SálRJ

\begin{abstract}
Resumo
Objetivo: Analisar a produção científica brasileira sobre a convivência da família com o portador de esquizofrenia. Método: Trata-se de uma revisão de bibliográfica realizada nas bases de dados Biblioteca Virtual de Saúde (BVS- BIREME) e biblioteca eletrônica Scientific Eletronic Library Online (Scielo). Resultados: Após análise dos dados, foi evidenciada a preocupação dos familiares com relação aos cuidados prestados aos entes esquizofrênicos e com as suas próprias necessidades, pois convivem com o portador de esquizofrenia diariamente. Conclusão: Percebe-se a importância da inserçấo do enfermeiro no cuidado a família do portador de esquizofrenia, proporcionando melhor qualidade de vida e promoção à saúde no ambiente familiar.
\end{abstract}

Palavras-chave: esquizofrenia, relaçôes familiares, cuidados de enfermagem.

\section{Abstract \\ Family living together with a person with schizophrenia}

Objective: To analyze the Brazilian scientific production on family living together with patient with schizophrenia. Method: This is a literature review which was conducted in Virtual Health Library (VHL-BIREME) and electronic library Scientific Electronic Library Online (SciELO) data bases. Results: After analyzing data, we noticed that families were very concerned about care provided to family member with schizophrenia and also about their own needs as they live together with this patient daily. Conclusion: We observed the importance to include nursing practice to care for families who have a person with schizophrenia, providing better quality of life and promoting health in the family.

Key-words: schizophrenia, family relations, nursing care.

\section{Resumen}

\section{La convivencia familiar con el enfermo esquizofrénico}

Objetivo: Analizar la producción científica brasileña sobre la convivencia familiar con el paciente con esquizofrenia. Método: Se trata de una revisión de la literatura que se realizó en las bases de datos de la Biblioteca Virtual en Salud (BVS-BIREME) y la biblioteca electrónica Scientific Electronic Library Online (SciELO). Resultados: Después de analizar 
los datos, se evidenció la preocupación de la familia con respecto a la atención prestada al paciente con esquizofrenia y con sus propias necesidades, una vez que conviven con la enfermedad a diario. Conclusión: Se percibe la importancia de la inclusión del enfermero en la atención a la familia con enfermo esquizofrénico, proporcionando mejor calidad de vida y promoción de la salud en la familia.

Palabras-clave: esquizofrenia, relaciones familiares, cuidados de enfermería.

\section{Introdução}

A esquizofrenia é um problema de saúde pública que exige investimento do sistema de saúde para a assistência ao esquizofrênico e à sua família. "A pessoa com transtorno mental encontra-se em uma condição vulnerável do ponto de vista da susceptibilidade das respostas ao contexto em que está inserida" [1:264]. A esquizofrenia é um transtorno mental grave que afeta praticamente todos os processos mentais e que se caracteriza em geral pela presença de ambivalência emocional, alucinaçôes, alteraçóes da forma e do conteúdo do pensamento (sobretudo delírios) e alteraçóes do contato com a realidade [2].

As transformaçóes vividas na assistência psiquiátrica nas últimas duas décadas criaram novas demandas para os serviços de saúde, bem como para os familiares dos portadores de esquizofrenia. Neste contexto as famílias se encontram afetadas e sobrecarregadas emocional e financeiramente, uma vez que tomaram funçóes que foram realizadas no passado pelas instituições psiquiátricas [3], desta forma, estas famílias tornaram-se também alvo de cuidados dos profissionais da área da saúde e das ciências humanas. Tais famílias encontram-se em situação de risco, pois a esquizofrenia, dadas as suas características e quando não devidamente controlada, sobrecarrega a família, já que ao manifestar suas diferentes alteraçóes transforma seu contexto e cotidiano [4,5]. A família precisa ser compreendida como uma unidade de cuidado, e compete aos profissionais de saúde apoiá-la e fortalecê-la quando esta se encontrar fragilizada. Assim, a abordagem em saúde mental não se restringe apenas à medicação e eventuais internaçóes, mas também a açôes e procedimentos que visem a uma reintegração familiar e social [6].

Os profissionais necessitam criar estratégias para garantir um cuidado humanizado que ultrapasse o acolher, com garantias e que possa resgatar a cidadania náo só dos esquizofrênicos, mas também de suas famílias. Desta forma, os enfermeiros desempenham um importante papel no cuidado a estas famílias, uma vez que a prática de enfermagem necessita imprimir uma nova lógica à organização do trabalho, configurando um agir pautado na integralidade, o que deve ocorrer a partir da formação profissional, comprometida com a aquisição de habilidade e competências voltadas para esse campo [6].

Além da complexidade que envolve o conhecimento das necessidades específicas que possam apresentar as famílias de portadores de esquizofrenia e a importância das açóes de cuidado de enfermagem voltadas a elas, a insuficiência de publicaçôes sobre a temática justifica a realização deste estudo. Diante da importância de instrumentalizar os enfermeiros para uma assistência sistematizada e humanizada voltada para a família do portador de esquizofrenia, traçou-se como objetivo identificar a produção científica da enfermagem brasileira acerca da convivência das famílias com o indivíduo com esquizofrenia.

\section{Material e métodos}

Estudo de revisão bibliográfica desenvolvido a partir da identificação do tema e formulação da questão norteadora; determinação dos critérios de inclusão e exclusão de artigos (seleção da amostra); definição das informaçôes a serem extraídas dos artigos; avaliação dos resultados incluídos na revisão; interpretação dos resultados.

Para guiar a pesquisa, formulou-se a seguinte questão: de que forma se estabelece o convívio da família com um membro portador de esquizofrenia? Os critérios de inclusão foram: artigos publicados em periódicos de enfermagem, na íntegra em português, no período compreendido entre junho de 2002 e junho de 2012, sendo pelo menos um dos autores enfermeiro. Como critérios de exclusão foram: artigos que náo apresentavam o profissional 
enfermeiro como autor, artigos que apresentavam somente a publicação do resumo, artigos estrangeiros e artigos publicados em periódicos gerais.

Para a coleta de dados, foi elaborado um instrumento que contemplou: identificação do artigo, autores, metodologia, principais achados, periódico e o ano da publicação. O levantamento dos dados aconteceu no período de julho a agosto de 2012. Para a seleçáo dos artigos foi utilizada a as bases de dados da Biblioteca Virtual em Saúde (BVS-BIREME). Os descritores utilizados na busca dos dados foram esquizofrenia, relaçôes familiares, família. A referida busca foi realizada pelo acesso on-line, utilizando os critérios de inclusão, sendo constituída de 7 (sete) artigos encontrados na base de dados LILACS (Literatura Latino-Americana e do Caribe em Ciências da Saúde) e biblioteca eletrônica Scielo (Scientific Eletronic Librasy Online). Os resumos foram avaliados e as produçóes que atenderam os critérios previamente estabelecidos foram selecionadas e lidas na íntegra.

Após a leitura das pesquisas selecionadas na íntegra, prosseguiu-se com a análise e organização dos resultados, na perspectiva da análise temática [7].

\section{Resultados}

Foram encontrados 7 artigos científicos. A apresentação dos resultados está dividida em dois segmentos: o primeiro com uma tabela contemplando as informaçóes: autor, ano da publicação, periódico publicado e a metodologia abordada nos estudos, e o segundo com a síntese dos artigos pesquisados, destacando os autores, título e principais achados dos estudos.
Os artigos que compóem a amostra deste estudo foram publicados entre os anos de 2005 a 2012. Quanto à metodologia, a pesquisa qualitativa teve maior destaque entre os estudos. Com relação aos periódicos ressalta-se que dos 07 artigos, 03 foram publicados na Revista Brasileira de Enfermagem.

$\mathrm{Na}$ síntese dos artigos pesquisados, encontramos:

1) Teixeira MB. Qualidade de vida de familiares cuidadores do doente esquizofrênico. Principais achados: Os familiares definiram qualidade de vida como: ter saúde, poder trabalhar e sustentar a família; ter saúde; ter bons hospitais e morar em um bairro melhor; ter saúde e continuar tratando deles; ter saúde e casa própria; ter dinheiro para tratar melhor deles. Entre os fatores que interferiram em suas vidas o deixar de ir a igreja; não sair com amigos; deixar de trabalhar e não ter mais tempo para si mesmo foram os que sobressaíram.

2) Durão AMS, Souza MCBM, Miasso AI. Grupo de acompanhamento de portadores de esquizofrenia em uso de clozapina e de seus familiares: percepção dos participantes. Principais achados: Obteve-se que o grupo constituiu espaço oportuno para conversar e ouvir sobre a doença, trocar experiências; proporcionou maior segurança e autoestima para seus integrantes e melhora nos relacionamentos dos pacientes e constituiu ajuda terapêutica para os familiares. Tais resultados apontam a necessidade de um novo olhar para o portador de transtorno mental, no sentido de buscar atitudes terapêuticas mais adequadas que atuem na produção de vida.

Tabela I - Distribuição dos artigos segundo autor, ano da publicação, periódico e metodologia abordada nos estudos.

\begin{tabular}{|c|c|c|c|}
\hline Autor & $\begin{array}{c}\text { Ano de } \\
\text { publicação }\end{array}$ & Periódico & Metodologia \\
\hline Teixeira MB [8] & 2005 & Revista Brasileira de Enfermagem/DF & $\begin{array}{l}\text { Qualitativa, Descritivo, Exploratório, } \\
\text { Transversal. }\end{array}$ \\
\hline Durão AMS et al. [9] & 2005 & Revista Brasileira de Enfermagem/DF & $\begin{array}{l}\text { Pesquisa de Avaliação, Descritivo, Explo- } \\
\text { ratório. }\end{array}$ \\
\hline Durão AMS et al. [10] & 2006 & $\begin{array}{l}\text { Revista Latino-Americana de Enferma- } \\
\text { gem/SP }\end{array}$ & Qualitativa. \\
\hline Zanetti ACG et al. [1 1] & 2007 & Revista Gaúcha de Enfermagem/RS & Estudo de caso etnográfico. \\
\hline Sales CA et al. [12] & 2010 & $\begin{array}{l}\text { Revista Eletrônica de Enfermagem/ } \\
\text { GO }\end{array}$ & $\begin{array}{l}\text { Qualitativa, Abordagem fenomenológi- } \\
\text { ca existencial de Martin Heidegger }\end{array}$ \\
\hline Sales CA et al. [13] & 2011 & Revista Brasileira de Enfermagem/DF & Qualitativa, Abordagem fenomenológica. \\
\hline Oliveira RM et al. [14] & 2012 & $\begin{array}{l}\text { Revista da Escola de Enfermagem da } \\
\text { USP/SP }\end{array}$ & $\begin{array}{l}\text { Pesquisa de campo na vertente história } \\
\text { oral temática }\end{array}$ \\
\hline
\end{tabular}


3) Duráo MAS, Souza MCBM. Cotidiano de portadores de esquizofrenia, após uso de um antipsicótico atípico e acompanhamento em grupo: visão do familiar. Principais achados: Obteve-se melhora do paciente quanto aos sintomas da doença evidenciada pela diminuição do isolamento social, retomada de atividades domésticas/trabalho e estudo e participação em atividades de convívio social. Tais resultados apontam a necessidade de um novo olhar para o portador de transtorno mental e seus familiares, no sentido de buscar atitudes terapêuticas mais adequadas que atuem na produção de vida visando novo sentido para a existência, nas diferentes formas de convivência e de sociabilidade.

4) Zanetti ACG, Galera SAF. O impacto da esquizofrenia para a família. Principais achados: O impacto da esquizofrenia para a família foi revelado pelo sofrimento e pela sobrecarga dos pais, de modo particular da máe, e pelo isolamento do grupo.

5) Sales CA, Schülhi PAP, Santos EM, Waidman MAP, Narcon SS. Vivências dos familiares ao cuidar de um ente esquizofrênico: um enfoque fenomenológico. Principais achados: Dos discursos emergiram as seguintes temáticas: Vivenciando o preconceito ao Ser esquizofrênico; Compreendendo a facticidade existencial do outro; Aprendendo a conviver com o ente esquizofrênico; Experienciando vicissitudes pelos conflitos familiares. Essas temáticas revelam o cotidiano destes seres, enredado em angústias, incertezas, cansaço e desânimo, sentimentos associados a uma busca incessante por ressignificar sua existência.

6) Sales CA, Schülhi PAP, Santos EM, Tironi NM, D'artibale EF, Salci MA. Sentimentos de familiares sobre o futuro de um ser esquizofrênico: perspectivas para o cuidado de enfermagem. Principais achados: A análise suscitou uma temática central, A temporalidade de estar-com um ente esquizofrênico e, desta, três subtemas: Preocupando-se com o abandono, Experienciando a desesperança e a incerteza e Vivenciando a esperança de cura. $\mathrm{O}$ estudo despertou-nos, no universo do cuidado, para a importância do tempo, tantas vezes negligenciado por nós, profissionais da saúde, por não apreendermos o sentido dessa temporalidade na vivência dos seres de quem cuidamos.

7) Oliveira RM, Furegato ARF. Um casal de idosos e sua longa convivência com quatro filhos esquizofrênicos. Principais achados: Identificaram-se três categorias que retratam dificuldades vivenciadas no cotidiano, entendimento da esquizofrenia com sentido de limitaçóes, cansaço e sobrecarga com prejuízo da qualidade de vida, incerteza em relação ao futuro e resiliência fortalecida pela fé em Deus. A concepçáo de cuidado foi associada a procedimentos técnicos, mostrando satisfação com a atenção recebida.

\section{Discussão}

Os estudos mostraram de uma forma geral que há uma preocupação do familiar em oferecer um cuidado adequado ao ente esquizofrênico. "A família de indivíduos com esquizofrenia tem que se adaptar e lidar com o parente doente no dia-a-dia, desenvolvendo estratégias para cada situação" [9]. Neste sentido, a falta do conhecimento acerca da doença e suas manifestaçôes é um dos fatores geradores de estresse, sobrecarga e desgaste à família de um portador de esquizofrenia.

Desta forma, destaca-se o medo como um gerador de estresse e desgaste, uma vez que os cuidadores sentem-se inseguros em deixar o familiar portador de esquizofrenia sair sozinho, tendo como pano de fundo o medo da reaçáo dos outros, da discriminação, além do medo das reaçóes do próprio esquizofrênico em determinadas situaçóes, como com relação ao suicídio [15].

Outros fatores que geram medo nos familiares são: envelhecer, adoecer ou morrer e não ter quem cuidar do ente esquizofrênico. Este sentimento é expresso nas falas de mães que cuidam dos filhos esquizofrênicos. Geralmente as mães acham que estão ficando muito "velhas" e quando náo puderem mais cuidar dos filhos náo sabem quem cuidará dos mesmos [8].

Além do medo, outros sentimentos emergem quando é abordada a relação da família com o esquizofrênico. Familiares em alguns momentos demonstram raiva, falta de paciência, angústia, irritabilidade, ciúmes, falta de tolerância, preconceito, sentimento de culpa, compaixáo, demonstrando, assim, que também precisam de cuidados.

Outras preocupaçóes apontadas pelas famílias estáo relacionadas à mudança na dinâmica familiar e vida social.

Quanto à vida familiar, a situação financeira é a mais ressaltada nos estudos realizados. Muitos portadores de esquizofrenia nunca trabalharam e outros por sua vez eram os mantenedores da família. "No 
discurso dos cuidadores, as falas apontaram para o custo do tratamento, a diminuição da produtividade dos pacientes e a interferência na atividade profissional dos cuidadores" [15:76]. A situação financeira é um fator preocupante, principalmente para famílias de baixa renda, uma vez que sustentar um familiar com algumas limitações pesa no orçamento doméstico. Com relação às despesas provocadas pelo tratamento, "em função da irregularidade no fornecimento de medicação e da dificuldade com o transporte, os custos com a esquizofrenia muitas vezes recaem sobre os cuidadores" [15:76].

Outra situação apontada como fator desgastante foi a mudança da rotina da família para atender as necessidades do ente esquizofrênico: realizar higiene pessoal, administraçáo do medicamento, cuidar do dinheiro recebido por alguns, dedicar tempo ao esquizofrênico, acompanhar em consultas periódicas, além dos afazeres domésticos, como, fazer comida, cuidar da casa, fazer compras, pagar contas, trabalhar, entre outros [16].

Com relaçáo à vida social, os estudos apontam que o lazer é o primeiro a ser sacrificado, ficando assim qualidade de vida dos familiares comprometida. Em um estudo realizado por Teixeira [8], mostra que a maioria dos respondentes se afastou de amigos e de qualquer atividade social que tinham anteriormente ao diagnóstico do familiar. Neste caso, a família fica sobrecarregada e desgastada devido às consequências da alteraçáo da rotina e dos projetos de vida, da diminuiçáo da vida social, da supervisão de comportamentos problemáticos, dentre outros. O cuidado com o paciente portador de um transtorno mental grave requer adaptaçóes na vida diária, e os cuidadores acabam por desistir ou mudar os seus objetivos, deixando de viver sua realidade e passando a viver uma realidade construída a partir do convívio com o paciente [15].

A sobrecarga da família com relação ao cuidado ao parente esquizofrênico ficou evidente nos estudos apresentados. Desta forma, os familiares precisam ser enxergados como um grupo que necessita de cuidados específicos, segundo suas necessidades. E para esta assistência, é importante uma avaliação das necessidades da família antes do início de qualquer programa de intervençáo [17].

Neste sentido, faz-se necessário um grupo multiprofissional de apoio efetivo as famílias, no qual o profissional enfermeiro enquanto participante do grupo adquira subsídios através da fala dos membros da família.

\section{Conclusão}

Frente aos achados, percebe-se que apesar da sobrecarga advinda da convivência com o familiar esquizofrênico há a preocupação com os cuidados a serem prestados e interesse pelos grupos de apoio. Com isso, torna-se importante a inserção do enfermeiro no cuidado a família do portado de esquizofrenia, proporcionando melhor qualidade de vida e promoção à saúde no ambiente familiar, além de criar estratégias para que mais famílias possam aderir aos grupos destinados a elas.

Embora seja importante a prestação de um cuidado adequado ao portador de esquizofrenia, a família também deve ser alvo de uma atenção especial, com espaço para que possa manifestar suas ansiedades, medos, dúvidas, entre outras situaçóes vivenciadas. Destaca-se ainda a necessidade de novos estudos que sirvam de auxílio para o cuidado a família do portador de esquizofrenia preenchendo lacunas ainda existentes.

\section{Referências}

1. Luz PO, Guimarães J. Ética e bioética: contribuição para o debate da pesquisa em enfermagem psiquiátrica. Enfermagem Brasil 2007;6(4):260-6.

2. Abc.Med.Br. Esquizofrenia. $\mathrm{O}$ que saber sobre ela? [citado 2013 Mai 8]. Disponível em URL: http://www. abc.med.br/p/psicologia.

3. Clark RE, Drake RE. Expenditures of time and money by families of people with severe mental illness and substance use disorders. Community Mental Health Journal 1994;30(2):145-63.

4. Marcon SS, Radovanovic CAT, Waidman MAD, Oliveira MLF. Vivências e reflexóes de um grupo de estudos junto às famílias que enfrentam situaçóes de doença crônica de saúde. Texto Contexto Enferm 2005;14(n. esp.):116-24.

5. Silva KVLG, Monteiro ARM. A família em saúde mental: subsídios para o cuidado clínico de enfermagem. Rev Esc Enferm USP 2011;45(5):1237-42.

6. Bielemann VLM, Kantorski LP, Borges LR, Chiavagai FG, Willrich JQ, Sousa AS, et al. A inserção da família nos centros de atenção psicossocial sob a ótica de seus atores sociais. Texto Contexto Enferm 2009;8(1):131-9.

7. Bardin L. Análise de conteúdo. Lisboa: Edições 70; 2002.

8. Teixeira MB. Qualidade de vida de familiares cuidadores do doente esquizofrênico. Rev Bras Enferm 2005;58(2):171-5.

9. Durão MAS, Souza MCBM, Miasso AI. Grupo de acompanhamento de portadores de esquizofrenia em uso de Clorazapina e de seus familiares: percepçáo dos participantes. Rev Bras Enferm 2005;58(5):5248. 
10. Durão MAS, Souza MCBM. Cotidiano de portadores de esquizofrenia após uso de um antipsicótico atípico e acompanhamento em grupo: visão do familiar. Rev Latinoam Enferm 2006;14(4):586-92.

11. Zanetti ACG, Galera SAF. O impacto da esquizofrenia para a família. Rev Gaúch Enferm 2007;28(3):385-92.

12. Sales CA, Schuhli PAP, Santos M, Waidman MAP, Narcon SS. Vivências dos familiares ao cuidar de um ente esquizofrênico: um enfoque fenomenológico. Rev Eletretronica Enferm 2010;12(3):456-63.

13. Sales CA, Schulhi PAP, Santos EM, Nayara MT, D'Artibale EF, Salci MA. Sentimentos de familiares sobre o futuro de um ser esquizofrênico: perspectivas para o cuidado de enfermagem Rev Bras Enferm 2011;64(3):551-7.
14. Oliveira RM, Ferreira ARF. Um casal de idosos e sua longa convivência com quatro filhos esquizofrênicos. Rev Esc Enferm USP 2012;46(3):618-25.

15. Almeida MM, Schal VT, Martins AM, Modena CM. A sobrecarga de cuidadores de pacientes com esquizofrenia. Rev Psiquiatr Rio Grande do Sul 2010;32(3):73-9.

16. Souza Filho MD, Sousa AO, Parente ACBV, Martins MCC. Avaliação da sobrecarga em familiares cuidadores de pacientes esquizofrênicos adultos. Psicologia em Estudo 2010;15(3):639-47.

17. Scazufca M. Abordagem familiar em esquizofrenia. Rev Bras Psiquiatr 2000;22(supl I):50-2.

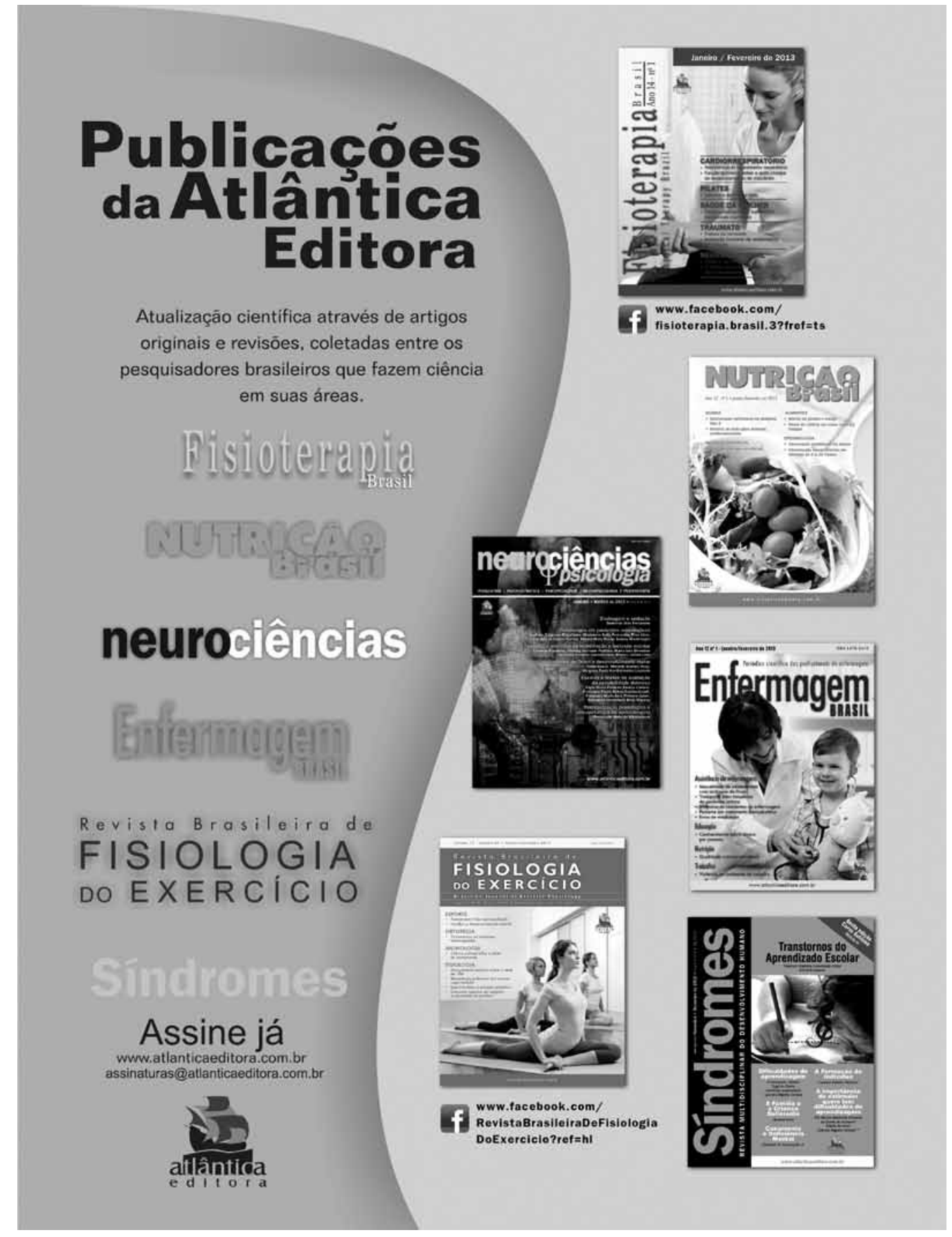

